\title{
Planejamento tributário eficiente: uma análise de sua relação com o risco de mercado
}

Efficient tax planning: an analysis of its relationship with the market risk

Planificación fiscal eficiente: un análisis de su relación con el riesgo de mercado

\section{André Pinto Coelho Vello}

Mestre em Planejamento Tributário pela FUCAPE Business School

Consultor em Finanças e Negócios da ALLANIS Business Consulting e Professor

Temporário na FUCAPE Business School

Endereço: Rua Ludwick Macal, no390, Bairro Jardim da Penha

CEP: 29060-030 - Vitória/ES - Brasil

E-mail: vello@allanis.com.br

Telefone: (27) 3207-3370

\section{Antonio Lopo Martinez}

Doutor em Controladoria e Contabilidade pela USP

Professor da FUCAPE Business School

Endereço: Av. Fernando Ferrari, 1358. Bairro Boa Vista

CEP: 29075-505 - Vitória/ES - Brasil

E-mail: lopo@fucape.br

Telefone (27) 4009-4444

Artigo recebido em 01/02/2014. Revisado por pares em 15/04/2014. Reformulado em 30/07/2014. Recomendado para publicação em 29/07/2014 por Sandra Rolim Ensslin (Editora Científica). Publicado em 28/08/2014. 


\title{
Resumo
}

Este artigo evidencia se um bom planejamento tributário promove uma redução do risco de mercado, desde que feito na presença de boas práticas de Governança Corporativa. Com base em uma amostra de 86 empresas de capital aberto listadas na BOVESPA e uma série histórica de cinco anos, efetuaram-se as regressões dos dados em painel, buscando identificar as variáveis que explicavam o risco de mercado (beta). Os resultados evidenciam a existência de uma relação significativa e negativa entre o risco de mercado e o índice de planejamento tributário eficiente das organizações nas empresas com melhores práticas de Governança Corporativa.

Palavras-chave: Planejamento tributário. Governança corporativa. Risco de mercado.

\begin{abstract}
This article shows if a good tax planning, promotes a reduction of market risk, when in presence of good corporate governance practices. From a sample of 86 publicly traded companies listed on the BOVESPA during a time lapse of 5 years is data panel of regressions in order to identify the variables that explain the market risk (beta). The results show the existence of a significant and negative relationship between market risk and the rate of efficient tax planning organizations, in companies with the best corporate governance practices.
\end{abstract}

Keywords: Tax avoidance. Corporate governance. Market risk.

\section{Resumen}

En este artículo si muestra que una buena planificación fiscal, promueve una reducción del riesgo de mercado, cuando en presencia de prácticas de buen gobierno corporativo. De una muestra de 86 empresas que cotizan en bolsa que figuran en la BOVESPA, durante un lapso de tiempo de 5 años es de panel de datos de las regresiones a fin de identificar las variables que explican el riesgo de mercado (beta). Los resultados muestran la existencia de una relación significativa y negativa entre el riesgo de mercado y el tipo de organizaciones de planificación fiscal eficiente, en las empresas con las mejores prácticas de gobierno corporativo.

Palabras clave: Planificación fiscal. Gobierno corporativo. Riesgo de mercado. 


\section{Introdução}

No Brasil, de acordo com o Instituto Brasileiro de Planejamento Tributário (IBPT), a carga tributária cresceu significativamente nos últimos anos. Entre 2000 e 2010, subiu de $30,03 \%$ para o representativo valor de 35,04\% do Produto Interno Bruto (PIB). O aumento nominal da arrecadação em 2010, em relação ao ano anterior, foi recorde, alcançando 17,80\% (AMARAL et al., 2011). Para fins comparativos, de acordo com os dados do Organization for Economic Co-Operation and Development (OECD), os Estados Unidos possuíam em 2008 uma carga equivalente a $27 \%$ do PIB (RECEITA FEDERAL DO BRASIL, 2010).

Diante dessas perspectivas, as organizações aqui estabelecidas vêm, ou podem vir a querer, aumentar seus investimentos em atividades que proporcionem a redução, ou diferimento dos tributos, o que a literatura internacional denomina de corporate tax avoidance. Se por um lado, as práticas de tax avoidance podem trazer reflexos positivos às organizações maximizando seu fluxo de caixa, por outro podem torná-las alvos potenciais das autoridades fiscais e das penalidades por elas impostas, com efeitos negativos ao fluxo de caixa da firma (HANLON; HEITZMAN, 2010, p. 145). Tornam-se assim relevantes as pesquisas sobre essa matéria, principalmente aquelas que venham a trazer mais esclarecimentos sobre as consequências dessas práticas às organizações.

A literatura sobre o tema é relativamente nova. De acordo com Hanlon e Heitzman (2010, p. 139), poucos estudos se propuseram a avaliar as consequências do tax avoidance às medidas de performance das organizações, sejam elas alcançadas pelas boas práticas de planejamento tributário lícito, ou mesmo por meios abusivos. Wilson (2009) e Desai e Dharmapala (2009) encontraram evidências significativas de que a prática de tax avoidance em conjunto com a de governança corporativa trazem mais retorno anormal às organizações e mais valor às firmas, respectivamente. Recentemente Ayers et al. (2010) encontraram evidências que sugerem haver relação significativa entre as variações positivas ou negativas do Book-Tax Difference (BTD) com uma tendência de piora em seu risco de crédito. Tais variações evidenciam pioras na qualidade do lucro da firma.

A gestão tributária talvez possa incrementar o arsenal de competitividade das organizações modernas, como ferramenta importante ao planejamento estratégico das firmas, tendo em vista o oneroso custo tributário atual e, ainda, uma fiscalização cada vez mais ativa, aparelhada e eficiente. Ainda carecem de estudos que tragam mais esclarecimentos sobre as consequências dessa prática às empresas.

Nesse contexto, pretende-se responder à seguinte pergunta: o risco de uma organização percebido pelo mercado financeiro é influenciado pelo nível de eficiência em planejamento tributário das empresas? Têm-se por objetivos específicos: (a) relacionar os conceitos de planejamento tributário trazidos por Scholes e Wolfson (1992) com os conceitos de tax avoidance e governança; e, (b) propor uma definição e um constructo à variável, planejamento tributário eficiente, além de um modelo para sua estimação.

Se, de um lado, pode haver organizações ineficientes em matéria tributária, essas empresas teriam assim um ônus tributário maior do que os outros competidores do setor. Dada a magnitude do custo fiscal das empresas brasileiras, imagina-se que essa ineficiência prejudique a capacidade competitiva da organização e aumente seu risco em relação às suas rivais. O mercado atual exige empresas competitivas que saibam se planejar com eficiência. Por outro lado, também existem as organizações que se expõem em excesso aos riscos. 
Os administradores que promovem tax avoidance pela prática da evasão ou elisão fiscal abusiva, por se exporem em demasia aos riscos legais, fazem com que suas organizações sejam vistas com maior grau de risco pelo mercado de capitais. Essa exposição ao risco legal, quando obscura e incerta, propicia ao mercado dúvidas sobre a eficiência do planejamento tributário realizado e incertezas quanto ao fluxo de caixa futuro da organização.

Para Hafkenscheid (2010), as despesas com tributos, isoladamente, não permitem avaliar o risco e podem, assim, conduzir a superestimar ou subestimar o valor econômico da posição fiscal da corporação. Proposições mais recentes sobre corporate tax avoidance sugerem avaliá-lo em conjunto com o nível de governança corporativa da firma. A transparência propiciada pela governança reduz os efeitos inerentes aos conflitos de agência e as incertezas do mercado sobre os passivos tributários ocultos da firma.

O planejamento tributário eficiente é definido como sendo o conjunto de ações que promovam reduções dos tributos explícitos da empresa, exercidas dentro dos preceitos das boas práticas de governança corporativa, que não façam avançar outros custos ou tributos com efeitos marginais superiores às reduções alcançadas, e que ao serem implementadas geram maior eficiência tributária à firma.

Este trabalho propõe-se a verificar a associação do risco sistemático como proxy do risco percebido pelo mercado financeiro com a proxy e o constructo para o planejamento tributário eficiente, tendo por base as definições e os conceitos de tax avoidance e de governança corporativa, abordados em conjunto. Outras variáveis instrumentais são utilizadas como medidas de controle aos métodos estatísticos propostos.

Como resultados, foram encontradas evidências que sugerem a existência de uma relação significativa e negativa entre o risco de mercado e o índice de planejamento tributário eficiente das organizações naquelas empresas com as melhores práticas de governança corporativa. A pesquisa revela o papel ativo desempenhado pela governança corporativa na garantia dos efeitos positivos de um planejamento tributário eficiente, indicando pontos de convergência desses conceitos.

$\mathrm{O}$ restante do artigo foi organizado da seguinte forma. Na segunda parte, aborda-se o referencial teórico e apresenta-se a hipótese de pesquisa. Na terceira parte, define-se a metodologia do trabalho, o modelo, os testes estatísticos e a mensuração das variáveis dependentes, independentes e de controle do modelo. Por fim, na quarta parte, apresentam-se os resultados alcançados, analisando-os, e, no final, apresentam-se as conclusões desta pesquisa.

\section{Revisão de Literatura}

\subsection{Fatores Determinantes de Risco de Mercado das Empresas Brasileiras}

Muitas pesquisas realizadas no Brasil e no exterior buscaram evidências entre as relações de riscos de mercado de uma organização com os seus dados contábeis, seus indicadores financeiros, de gestão ou de mercado. Dentre muitas pesquisas sobre a matéria no cenário internacional, podemos citar Hou e Robinson (2006), Gruca e Rego (2005) e Tuli e Bharadwaj (2009). Estas duas últimas pesquisas encontraram evidências da existência de relações negativas entre a satisfação do cliente e o risco, utilizando uma metodologia robusta com base no modelo de Famá e French (1992). Já a primeira, desenvolvida por Hou e 
Robinson (2006), concluiu que as organizações inseridas em setores com maior concentração possuem maior retorno anormal, pressupondo maior risco.

Concentrando-se agora no Brasil, também se observaram pesquisas empíricas sobre a matéria, relativamente recentes, conduzidas por: Dantas et al. (2005), Coser et al. (2005), Fernandes (2007) e outros. Dantas et al. (2005) encontraram evidências de que a variável alavancagem operacional é um fator determinante para a mensuração do risco sistemático das empresas com ações listadas na BOVESPA, e que quanto maior for a alavancagem operacional da empresa, maior seu retorno anormal, pressupondo maior risco. Coser et al. (2005), por sua vez, não encontraram relações significativas entre a alavancagem financeira e o risco de mercado das empresas com ações negociadas na BOVESPA.

Em seu estudo empírico sobre os fatores determinantes do risco de mercado das empresas brasileiras, Fernandes (2007) buscou evidências que o relacione com as variáveis de medidas de liquidez, de rentabilidade, de endividamento, de porte, do setor de atividade e, por fim, de governança corporativa. Utilizou regressões lineares seccionais simples e múltiplas, tendo como variável dependente o beta de um conjunto de empresas listadas na BOVESPA. Segundo a autora, os resultados desse estudo concluíram que a alavancagem financeira, tamanho dos ativos, variabilidade da liquidez são fatores que elevam o risco de mercado; já a rentabilidade, a variabilidade da alavancagem financeira, a variabilidade da rentabilidade e o crescimento dos ativos são fatores que reduzem o risco de mercado.

\subsection{Teoria de Planejamento Tributário e o Arcabouço de Scholes e Wolfson}

A estrutura conceitual desenvolvida por Scholes e Wolfson (1992) revolucionou a teoria de planejamento tributário em todo o mundo, à medida que trouxe à matéria três alicerces fundamentais para a realização de um planejamento tributário eficiente: all parts, all taxes, e all costs.

O conceito de eficiência, até então fragmentado, levou a se avaliarem as ações em planejamento tributário de uma forma nova, mais responsável e abrangente. Um planejamento tributário eficiente deve levar em consideração todas as partes envolvidas no processo, todos os tributos, sejam eles implícitos ou explícitos, e todos os custos relacionados, ainda que incertos ou prováveis. Destacam eles ainda que o tributo é apenas um dentre todos os demais custos de uma organização que podem sofrer influências do planejamento tributário proposto. (SCHOLES et al., 2014).

Nesse trabalho, os pesquisadores utilizaram os conceitos da teoria de risco e retorno para definir o que chamaram de implicit taxes. Trata-se da diferença marginal do custo de aquisição de um ativo, que oferecia uma determinada taxa de retorno, em relação ao que ele passou a valer após sofrer uma alteração em sua tax rate (SCHOLES et al., 2014).

Também trouxeram o conceito de tax clienteles cuja definição é bem próxima de implicit taxes. Enquanto que esta capta o efeito marginal do custo do Ativo antes e depois de uma alteração em sua carga tributária (time-section), aquela extrai essa diferença comparando-o a um ativo similar (cross-section), de mesmo risco, e subtraindo o efeito da diferença do custo transacional (SCHOLES et al., 2014).

Esses dois conceitos introduzidos têm como premissa a teoria de mercados eficientes, ausência de arbitragem, salvo pelo custo transacional, teoria do equilíbrio dos preços e a teoria de risco e retorno. As explicações para o implicit taxes e tax clienteles são as mesmas e são embasadas na teoria de finanças. Trata-se do valor marginal agregado ao ativo na 
proporção do seu fluxo de caixa livre descontado, quando há uma variação marginal da carga tributária efetiva desse ativo, no tempo ou no espaço, ou seja, entre os ativos.

Conjectura-se se, de forma inter-relacional, essa teoria poderia incrementar a teoria de risco ao levar essas novas concepções da matéria tributária como fator relevante para a sua compreensão, análise e evidenciação empírica. Até então, a teoria de precificação de ativos em finanças aborda a matéria tributária considerando apenas a carga tributária explícita do ativo, revertendo o seu benefício sobre a dívida de terceiros contraída pela empresa, o que se chama no modelo de tax shield.

Eventualmente, o planejamento tributário poderá provocar outros efeitos no que toca à precificação do ativo, que não apenas o tax shield. investiga-se aqui se ele também influencia o risco de mercado da firma e, por consequência, seu custo do capital próprio. Por último, Scholes et al. (2014) estabeleceram como mais um dos alicerces do planejamento tributário a perspectiva all costs. Nesse ponto, sugerem que, num plano fiscal, os gestores devem monitorar todos os custos, inclusive eventuais acréscimos de outros custos que esse processo pode vir a trazer indiretamente para a empresa.

\subsection{Corporate Tax Avoidance}

Segundo Hanlon e Heitzman (2010, p. 137), não existe uma definição universalmente aceita, ou um constructo, para o termo corporate tax avoidance. Pesquisas propondo uma nova perspectiva sobre a matéria são recentes e foram inicialmente idealizada por Slemrod (2004), Chen e Chu (2005) e Crocker e Slemrod (2005), pioneiros ao tratar do tema corporate tax avoidance com a teoria da agência desenvolvida por Jensen e Meckling em 1976.

Crocker e Slemrod (2005) ao abordarem o tema concluíram que as penalidades impostas aos gerentes tributários das organizações são mais eficientes em reduzir a sonegação do que aquelas impostas aos acionistas. Chen e Chu (2005), por sua vez, trouxeram à matéria os custos (explícitos) adicionais que incorrem os acionistas das firmas que praticam tax evasion, para manter o controle sobre seus administradores.

Além do mais, muitos dos fatores determinantes constatados no individual tax avoidance mantêm-se aplicável também ao corporate tax avoidance (HANLON; HEITZMAN, 2010). Dentro do tema fazem-se presentes os estudos de Richardson (2006), Tsakumis et al. (2007) e Richardson (2008) que investigaram os fatores individuais e sociais determinantes para o individual tax avoidance. Os fatores determinantes observados foram: o grau de instrução, a complexidade tributária, o tipo de atividade exercida, o senso de justiça e moral (RICHARDSON, 2006); a aversão à incerteza, a distância do poder, a masculinidade e a individualidade (TSAKUMIS et al., 2007); além do sistema legal, da confiança no governo e da religiosidade (RICHARDSON, 2008).

Os fatores individuais, contudo terão mais ou menos influência na organização dependendo de sua estrutura de propriedade e controle. Todavia faz-se importante observar que tax avoidance não é exatamente um reflexo do problema de agência, ou sequer o problema em si. Separar a estrutura de propriedade e controle dentro do tema tributário pode ser interessante para melhor compreendê-lo, em vista dos interesses conflitantes da organização e de seus administradores. (HANLON; HEITZMAN, 2010).

Conclui-se este tópico abordando as consequências que corporate tax avoidance pode trazer às organizações. Dentre os estudos que se propuseram a investigar esse tema, podemos citar alguns mais recentes como: Ayers et al. (2010), Wilson (2009) e Desai e Dharmapala 
(2009). Wilson (2009) encontrou evidências significativas de que a prática de tax avoidance em conjunto com a de governança corporativa, e apenas em conjunto, trazem maior retorno anormal às organizações. Um outro estudo, desenvolvido por Desai e Dharmapala (2009), encontrou evidências de que ações em tax avoidance, quando realizadas em conjunto com a governança, trazem maior valor às firmas. todavia, evidências empíricas estimadas no estudo sugerem que essa relação deixa de ser significativa quando não é levada em consideração a prática de governança exercida pela corporação.

Destaca-se a falta de um constructo universalmente aceito e capaz de captar adequadamente os efeitos da variável, conforme constatou Hanlon e Heitzman (2010). Citam em seu trabalho as dificuldades que esses constructos têm em captar os efeitos de conforming avoidance, com exceção das medidas extraídas do disclosered, ou das medidas que alcançam uma captação do efeito marginal (Marginal Tax Rate). Definem conforming avoidance como os efeitos capturados pelo constructo de tax avoidance quando sua ação é exercida sobre o resultado contábil da empresa.

\subsection{Hipótese de Pesquisa}

Pretende-se, neste trabalho, pesquisar a existência de uma relação entre o risco e a eficiência tributária das empresas. Tal investigação pode ajudar a explicar os motivos pelos quais nem toda ação com efeitos a redução (aumento) da tax rate de um ativo fazem aumentar (diminuir) seu valor perante o mercado, ou o aumenta (reduz) em maior (menor) proporção que os efeitos provocados pelo fluxo de caixa descontado do ativo.

Wilson (2009) e Desai e Dharmapala (2009), quando abordaram o tema sem a variável de governança, não encontraram os efeitos de maior retorno anormal dos ativos e maior valor, respectivamente, para as firmas que praticam o tax avoidance. Provavelmente pelos efeitos adversos que tax avoidance pode trazer ao risco de mercado dos ativos, quando não controlado. A variável governança foi introduzida ao modelo justamente com o objetivo de levar transparência ao mercado, e delimitar a estrutura de controle, propriedade e a sobreposição dos interesses dos administradores ao da firma, o conflito dos agentes. Essa variável vem atenuar a ocorrência do risco legal, posto que a transparência por ela trazida junto com o alinhamento dos interesses dos controladores aos dos administradores coíbem o surgimento do risco legal, quando promovida uma ação de planejamento tributário na empresa.

Estima-se que o risco de mercado de uma empresa deve ser tão menor quanto maior for o seu nível de eficiência tributária alcançado pelo planejamento tributário eficiente, e desde que controlado o conflito dos agentes, ou seja, a sobreposição dos interesses dos administradores aos dos proprietários.

Empresas ineficientes em matéria tributária devem ser percebidas pelo mercado com maior nível de risco, dado sua gestão ineficiente. Entende-se que nesta situação o risco de mercado é maior em função do aumento do risco operacional da firma. Já as empresas eficientes em matéria tributária, desde que controladas por práticas de governança que venham a tranquilizar o mercado informando-o de forma transparente da eficácia do planejamento realizado, devem ser percebidas com menor nível de risco, dada sua eficiência em gestão. Entende-se que, nessa situação, o risco de mercado é menor em função da redução do risco operacional da firma, sendo aqui controlado o risco legal pelas práticas de governança adotadas na empresa. Assim, tem-se esta hipótese de pesquisa neste trabalho: 
Hipótese 1:

Quanto maior for o nível de eficiência em planejamento tributário de uma empresa na presença de boas práticas de Governança Corporativa, menor será o seu risco em relação ao mercado financeiro.

Hanlon e Heitzman (2010) destacam que as pesquisas feitas sobre o tema devem tomar cuidado com as conclusões que inferem, em vista dos constructos que utilizam. No recorte proposto ao trabalho, o constructo utilizado deve ser capaz de perceber os interesses da firma separadamente da influência dos agentes, segregando a estrutura de propriedade e controle da organização. Para tal ação faz-se imprescindível que nele contenham as influências da variável de governança, em linha com a teoria de corporate tax avoidance.

Trata-se sim de uma "redução" intencional ao all parts, pois o interesse desta pesquisa é relacionado às consequências e influências que o planejamento tributário traz, exclusivamente, às empresas. Não obstante, o constructo deve ser capaz de absorver os demais conceitos de Scholes et al. (2014), all taxes e all costs. Nesse contexto, torna-se fundamental a utilização de um que tenha a percepção de todos os efeitos, ou seja o conforming avoidance, tax clienteles, implicit taxes e carga tributária oculta.

\section{Metodologia}

A metodologia de pesquisa utilizada neste trabalho é descritiva e exploratória, pois além de descrever as relações entre variáveis, explora a proposição de um constructo para planejamento tributário eficiente.

\subsection{Dados}

Os dados para a realização da pesquisa foram coletados em três fontes específicas: (a) os dados dos relatórios de demonstrativos de valor agregado (DVA) das empresas brasileiras de capital aberto listadas no BOVESPA, e que responderam à pesquisa da revista Exame, da Editora Abril, denominada Melhores \& Maiores, dentre os anos de 2005 e 2009, dados estes que foram gentilmente cedidos pela FIPECAFI/USP, instituição que desenvolve a análise para a realização deste trabalho; (b) os dados dos relatórios financeiros das empresas, obtidos na base de dados do Economática Brasil, e, (c) os dados do nível de governança corporativa, conforma classificação dada pela CVM, obtidos na página da BM\&FBOVESPA, das empresas que compõem o Índice Teórico de Governança Corporativa (IGC), elaborado e acompanhado por essa instituição.

Tabela 1- Resumo da amostra utilizada no trabalho

\begin{tabular}{|c|c|c|c|c|c|c|}
\hline Setor Economática: & 2005 & 2006 & 2007 & 2008 & 2009 & Total \\
\hline Alimentos e Bebidas & & & & 6 & 8 & 14 \\
\hline Comércio & & & 5 & 6 & 10 & 21 \\
\hline Energia Elétrica & 11 & 11 & 13 & 13 & 12 & 60 \\
\hline Petróleo e Gás & 5 & & & & & 5 \\
\hline Química & 8 & 7 & 6 & 6 & 7 & 34 \\
\hline Siderurgia \& Metalurgia & 9 & 8 & 8 & 7 & 7 & 39 \\
\hline Têxtil & & & 5 & 9 & 10 & 24 \\
\hline
\end{tabular}




\begin{tabular}{lrrrrrr}
\hline Veículos e peças & 5 & 5 & & 8 & 8 & 26 \\
Total & 38 & $\mathbf{3 1}$ & $\mathbf{3 7}$ & $\mathbf{5 5}$ & $\mathbf{6 2}$ & $\mathbf{2 2 3}$ \\
\hline
\end{tabular}

Fonte: Dados da pesquisa.

Foram excluídas da amostra as empresas cujo setor e ano ficaram inferiores a cinco, as empresas que tiveram uma representatividade inferior a $10 \%$ do total de empresas daquele setor e o setor classificado como "OUTROS" pelo banco de dados do Economática. A exclusão desses dados foi feita com dois objetivos: (1) primar por uma boa representatividade das empresas em dado setor e anos, buscando assim um erro menos significativo entre a carga tributária daquele setor e a calculada pela média das cargas tributárias das empresas ali contidas; e, (2) excluir empresas sem bases comparáveis. A seguir, apresenta-se em resumo a quantidade de empresas por ano e setor referente à amostra de dados utilizada no trabalho, após as referidas exclusões.

\subsection{Estimação da Variável Independente - Tax Avoidance}

Antes de adentrar na mensuração do índice de planejamento tributário eficiente da empresa propriamente dita, faz-se necessário trazer alguns conceitos contábeis e pesquisas realizadas.

\subsubsection{Demonstrativo de Valor Adicionado - DVA}

O Demonstrativo de Valor Adicionado (DVA) tem como objetivo principal apresentar o valor da riqueza criada pela empresa, sejam por suas vendas de mercadorias, produtos ou serviços, ou pelos seus resultados não operacionais, receitas financeiras, resultados de equivalência patrimonial, dividendos recebidos, resultados de investimentos, aluguéis e royalties. É também prestada pela DVA a informação de como esta riqueza foi distribuída às partes interessadas, ou seja, aos fornecedores, empregados, governo (impostos), financiadores e sócios ou acionistas. Em todos os casos esta riqueza adicionada e distribuída é contabilizada pelo conceito contábil de valor agregado.

É bastante pertinente referenciar o caráter social desse demonstrativo, à medida que informa à sociedade o quanto a empresa gerou de recursos e como os distribuiu, informando se esta é uma organização que agrega valor ao local onde está inserida. Gallo (2008) propõe, assim, utilizá-la como forma de cálculo alternativa para mensuração da carga tributária de um país. Muitas empresas, mesmo desobrigadas, divulgaram e continuam divulgando essa demonstração, como uma forma de transparência das suas relações com o mercado.

\subsubsection{Mensuração da Carga Tributária Setorial}

Na DVA, é possível obter a taxa de tributo sobre o valor adicionado de uma empresa. Também é possível se obter a carga tributária de um setor ou mercado. Dividindo-se a parcela da riqueza da empresa distribuída ao governo, referente ao seu ônus tributário, pelo valor total da riqueza adicionada pela organização, tem-se a relação do imposto distribuído sobre a riqueza agregada dessa organização. Conforme Gallo (2008), quando se faz esse cálculo para o conjunto de empresas de um setor ou mercado, tem-se a carga tributária setorial ou do mercado. O somatório da carga tributária de todas as empresas, utilizando-se de seus 
microdados, seria significativamente representativo para estimar a carga tributária do país. Esse modelo de cálculo é oferecido como alternativa para o atual que utiliza o PIB e os dados de arrecadação fiscal fazendários.

Gallo (2008) promoveu ajustes em seus dados de forma a utilizar o "Valor Adicionado Líquido" para encontrar a relação do imposto distribuído sobre a riqueza agregada líquida dessa organização em vez do "Valor Total a Distribuir". A diferença entre os dois é a rubrica do DVA denominada de "Valor Adicionado Recebido em Transferência", que é composto pelos resultados financeiros e pelos resultados de equivalência patrimonial obtidos pela organização. Adota-se, portanto, como procedimento deduzir do cálculo o valor da equivalência patrimonial, tanto para a mensuração da carga tributária setorial (CTS) quanto para a mensuração do marginal tax rate (MTR) da empresa, pelo mesmo motivo.

Urge registrar, entretanto, que os resultados financeiros compõem base de cálculo para o IOF, para os tributos sobre o Lucro (IR e CSLL) e, eventualmente, para o PIS e COFINS, dependendo da opção do regime adotado pela empresa, sendo esta, inclusive, uma ação de planejamento tributário da empresa. Assim sendo, devem ser mantido, na pesquisa em pauta, seu valor na mensuração do MTR, e, da mesma forma na mensuração do CTS, em que se entende que o ganho ou a perda financeira é um resultado da organização, sendo as instituições financeiras meras prestadoras do serviço à empresa. Logo, será deduzido do cálculo apenas o resultado de equivalência patrimonial e mantidos os resultados financeiros. Realiza-se o cálculo com o denominador "Valor Adicionado Total a Distribuir" subtraído da "Equivalência Patrimonial" em vez do "Valor Adicionado Líquido". Desse modo, utilizam-se, nesta pesquisa, os dados da DVA das empresas para o cálculo da carga tributária de cada setor do Economática. A equação utilizada para o cálculo é apresentada a seguir:

$$
\mathrm{CTS}_{\mathrm{kt}}=\quad \sum_{i}^{N_{k t}} \frac{T_{i k t}}{\left(T V A D_{i k t}-E P_{i k t}\right)} \times N_{k t}
$$

Onde,

- $\mathrm{CTS}_{\mathrm{kt}}$ : Carga tributária do setor k e ano t;

- $\mathrm{T}_{\mathrm{ikt}}$ : Impostos, taxas e contribuições distribuídos da empresa i do setor k e ano t;

- $\mathrm{EP}_{\mathrm{ikt}}$ : Resultado auferido por equivalência patrimonial da empresa i do setor k e ano

$\mathrm{t}$

- TVAD $\mathrm{ikt}_{\mathrm{i}}$ Valor adicionado total a distribuir da empresa i do setor $\mathrm{k}$ e ano $\mathrm{t}$; e

- $\mathrm{N}_{\mathrm{kt}}$ : Quantidade de empresas por setor e ano.

Os resultados obtidos na mensuração da carga tributária setorial foram alcançados aplicando a equação (1) acima aos dados do trabalho, e seguem apresentados a seguir:

Tabela 2- Apresentação dos resultados obtidos pelo cálculo da carga tributária setorial

\begin{tabular}{|c|c|c|c|c|c|c|}
\hline & \multicolumn{6}{|c|}{$\mathrm{ANO}$} \\
\hline SETOR ECONOMÁTICA & 2005 & 2006 & 2007 & 2008 & 2009 & $\begin{array}{l}\text { Média } \\
\text { Setor }\end{array}$ \\
\hline Alimentos e Bebidas & & & & $26 \%$ & $22 \%$ & $24 \%$ \\
\hline Comércio & & & $42 \%$ & $41 \%$ & $42 \%$ & $42 \%$ \\
\hline Energia Elétrica & $44 \%$ & $51 \%$ & $55 \%$ & $34 \%$ & $49 \%$ & $46 \%$ \\
\hline Petróleo e Gás & $58 \%$ & & & & & $\mathbf{5 8 \%}$ \\
\hline
\end{tabular}


Planejamento tributário eficiente: uma análise de sua relação com o risco de mercado...

\begin{tabular}{|c|c|c|c|c|c|c|}
\hline Química & $29 \%$ & $41 \%$ & $24 \%$ & $24 \%$ & $39 \%$ & $32 \%$ \\
\hline Siderurgia \& Metalurgia & $35 \%$ & $38 \%$ & $39 \%$ & $31 \%$ & $21 \%$ & $33 \%$ \\
\hline Têxtil & & & $37 \%$ & $37 \%$ & $28 \%$ & $33 \%$ \\
\hline Veículos e peças & $14 \%$ & $20 \%$ & & $6 \%$ & $23 \%$ & $15 \%$ \\
\hline Média Ano & $37 \%$ & $41 \%$ & $42 \%$ & $29 \%$ & $33 \%$ & $35 \%$ \\
\hline
\end{tabular}

Fonte: Dados da pesquisa.

Foi utilizado esse cálculo no trabalho justamente por não terem sido localizados pelo autor dados públicos disponíveis sobre a carga tributária setorial. E também por esse motivo não é possível auferir se a carga tributária dessa amostra é representativa.

\subsubsection{Constructo de Tax Avoidance: Índice de Planejamento Tributário Eficiente (IPTE)}

Para a definição do constructo de tax avoidance da firma faz-se necessário, antes, definir o conceito e a forma de cálculo de marginal tax rate (MTR). Segundo Hanlon e Heitzman (2010), o MTR é uma das poucas medidas de tax avoidance propostas na literatura internacional capaz de perceber os efeitos de conforming avoidance já comentado. A medida de MTR é definida por Hanlon e Heitzman (2010, p. 140) como: "Present value of taxes on an additional dollar of income".

Dividindo os impostos distribuídos pela empresa pelo seu valor adicionado total, líquido da equivalência patrimonial, teremos uma medida marginal de impostos daquela firma no período. Como essa medida será comparada com outras apenas no mesmo lapso temporal, torna-se desnecessário ao cálculo aqui proposto a obtenção de seu valor presente.

Observa-se também o fato dessa variável não ser mensurada a partir do lucro contábil da empresa, constatação que se torna relevante como mais um argumento para não se refutar dessa variável os efeitos do conforming avoidance. Utiliza-se a equação (2) abaixo para expressar o método de cálculo para obtenção dessa variável.

$$
M T R_{i k t}=\left(\frac{T_{i k t}}{T V A D_{i k t}-E P_{i k t}}\right)
$$

Onde,

- $\mathrm{MTR}_{\mathrm{ikt}}$ : Marginal taxes rate da empresa i, setor k e ano t;

- $\mathrm{T}_{\mathrm{ikt}}$ Impostos, taxas e contribuições distribuídos da empresa i, setor k e ano t;

- $\mathrm{EP}_{\mathrm{ikt}}$ : Resultado auferido por equivalência patrimonial da empresa i, setor k e ano t;

e

- TVAD $\mathrm{ikt}_{\mathrm{i}}$ Valor adicionado total a distribuir da empresa i, setor k e ano t.

Para que se possa comparar essa variável entre os setores no mesmo ano, faz-se ainda necessário padronizá-la, ou seja, subtraí-la da carga tributária setorial, em um dado ano, e dividi-la pelo desvio padrão do setor e ano à qual pertence.

A carga tributária setorial foi obtida na equação (2) acima, mas também poderia ser obtida de algum relatório setorial, se disponível. Assim se calcula o MTR padronizado da firma conforme proposto na equação (3) a seguir:

$$
S M T R_{i k t}=\left(S T R_{k t}-M T R_{k t}\right) / \sigma_{k t}
$$


Onde,

- SMTR $_{\text {ikt: }}$ Variável MTR padronizada da empresa i, setor k e ano t;

- $\mathrm{CTS}_{\mathrm{kt}}$ : Carga tributária do setor k e ano t;

- $\mathrm{MTR}_{\mathrm{ikt}}$ : Marginal taxes rate da empresa i, setor k e ano t; e

- $\sigma_{\mathrm{kt}}$ : Desvio padrão da MTR no setor k e ano t.

Tal ação faz com que a variável retenha uma "memória" sobre os efeitos cross-section atrelados, tornando-a uma medida relativa, com bases comparáveis, e assim proporcionando a ela uma capacidade de percepção dos efeitos de tax clienteles.

Retomando os requisitos anteriormente abordados para a definição do constructo ideal para a variável planejamento tributário eficiente, ainda restam três ações. São elas: (a) restringi-lo aos efeitos inerentes à firma e evitar assim os interesses particulares e conflitantes dos demais agentes; (b) ter a percepção da carga tributária oculta; e, (c) ter a percepção do implicts taxes. Atua-se nos dois primeiros itens com a inclusão da governança corporativa ao constructo. Tal ação está devidamente embasada pela teoria atual, que evidencia a adoção dessa medida para que sejam segregadas da análise do fenômeno os efeitos adversos aos do interesse da empresa.

Ao se adicionar ao constructo a percepção de governança, também se amenizam os efeitos da carga tributária oculta por dois motivos: (1) elimina-se aquelas propositalmente impostos pelos agentes em vista dos seus interesses particulares e, (2) a governança traz à empresa mais transparência e, por conseguinte, estima-se que em organizações com alto nível de governança reduzem a ocultação de fatores, como os passivos fiscais ocultos.

Por último, abordando o implicts taxes, considera-se que, para ter seus efeitos percebidos pelo constructo, deveria ser inserida ao constructo uma função de long run, a exemplo da proposta feita por Dyreng et al. (2008). Nessa pesquisa, foi desenvolvido um constructo para a variável tax avoidance que denominaram de "long-run cash effective tax rate - ETR". Todavia, reconhece-se que, por não se terem dados temporais em quantidade satisfatória, não será atendido esse requisito na proposta do constructo desenvolvida, mas concedera-se sua utilização sempre que os dados possibilitarem.

Em termos matemáticos, segue a proposta feita para a inclusão de governança ao contexto do constructo:

$\mathrm{IPTE}_{\mathrm{ikt}}=-\mathrm{SMTR}_{\mathrm{ikt}} * \mathrm{IGC}_{\mathrm{ikt}}$, sendo IGC $=\left\{\begin{array}{r}1, \mathrm{SMTR}_{\mathrm{ikt}} \geq 0 \\ \mathrm{CGF}_{\mathrm{m}}, \mathrm{SMTR}_{\mathrm{ikt}}<0\end{array}, \mathrm{e}\right.$

\begin{tabular}{|c|c|c|c|c|}
\hline & Sem Governança & Nível 1 & Nível 2 & Novo Mercado \\
\hline $\mathrm{GF}_{\mathrm{m}}=$ & 0,1 & 0,85 & 0,9 & 1 \\
\hline
\end{tabular}

- IPTE $_{\mathrm{ikt}}$ Índice de planejamento tributário eficiente da empresa i, setor k e ano t;

- $\mathrm{SMTR}_{\mathrm{ikt}}$ : Variável MTR padronizada da empresa i, setor k e ano t;

- $\mathrm{IGC}_{\mathrm{kt}}$. Índice de governança corporativa da empresa i, setor k e ano t;

- $\mathrm{CGF}_{\mathrm{nm}}$ : Fator de atenuação pela evidenciação de menor nível de governança corporativa; e

- $\sigma_{\mathrm{kt}}$ : Desvio padrão da MTR no setor k e ano t. 
Explica-se aqui cada passo da equação (4) a seguir: Passo 1) para a variável com vistas a captar os efeitos de planejamento tributário, deve-se inverter o sinal, pois $\left(\mathrm{SMTR}_{\mathrm{ikt}}\right)$ é uma variável de tax rate; Passo 2) quando a empresa apresenta sua marginal tax rate padronizada positiva $\left(\mathrm{SMTR}_{\mathrm{ikt}}>0\right)$, planejamento ineficaz, desconsidera-se o efeito de governança. Entende-se que não há o que se falar em interesses particulares e carga tributária oculta nesta situação de baixa performance fiscal da empresa; Passo 3) quando o planejamento tributário for eficaz $\left(\mathrm{SMTR}_{\mathrm{ikt}}<0\right)$, aplica-se o fator de atenuação pela evidenciação de menor nível de Governança Corporativa $\left(\mathrm{CGF}_{\mathrm{m}}\right)$ conforme valores propostos. Este vetor traz os efeitos da governança corporativa ao modelo.

\section{Quadro 1- Apresentação dos requisitos idealmente propostos para a estimação do nível de planejamento tributário eficiente}

Atendimento do constructo proposto neste trabalho (IPTE) ao requisito.

1. Captar apenas os efeitos de interesse da firma, e evitar os interesses particulares e conflitantes dos demais agentes.

2. Ser capaz de perceber ações em planejamento tributário que alterem o lucro contábil da empresa (conforming avoidance).

3. Ser uma medida relativa, com bases comparáveis entre os ativos, e assim ter a percepção do tax clienteles (cross -section).

4. Ser uma medida relativa, com bases comparáveis no tempo, e assim ter a percepção dos implicit taxes (time-section).

5. Ter a percepção dos efeitos da carga tributária oculta.

Fonte: Dados da pesquisa.

Quando maior for o valor de $\mathrm{CGF}_{\mathrm{m}}$, significa que menor será a atenuação do IPTE, ou seja, estima-se que se tem transparência ao planejamento tributário proposto e assim não se atenuam seus efeitos. Assim sendo, considera-se o valor unitário quando a empresa estiver classificada no novo mercado, e o menor valor quando a empresa não tiver a classificação de governança da comissão de valores mobiliários (CVM).

Apresentou-se, no Quadro 1, um resumo dos requisitos entendidos como ideais para a estimação do constructo de tax avoidance, bem como atendimento, na qualificação do autor, que o constructo proposto (variável IPTE) alcançou em cada um dos requisitos estabelecidos.

E, para concluir essa parte, com base nos testes estatísticos de normalidade aplicados, evidencia-se que não há razões para se rejeitar que a variável IPTE, bem como as subvariáveis sobre a qual se origina, não sejam normais.

Tabela 3- Apresentação do teste de normalidade de Swapiro-Wilk aplicado às principais variáveis do modelo

\begin{tabular}{|c|c|c|c|c|}
\hline \multicolumn{5}{|c|}{ Teste de normalidade aplicado às principais variáveis do modelo } \\
\hline & MTR & SMTR & IPTE & RISCO \\
\hline $\boldsymbol{Z}$ & 7,037 & 2,164 & 4,236 & 2,097 \\
\hline p-value & $0,0 \%$ & $1,5 \%$ & $0,0 \%$ & $1,8 \%$ \\
\hline $\begin{array}{l}\text { Interpretação } \\
\text { teste }\end{array}$ & $\begin{array}{l}\text { Normalidade não } \\
\text { rejeitada ao nível de } \\
99,95 \% \text { confiança. }\end{array}$ & $\begin{array}{l}\text { Normalidade não } \\
\text { rejeitada ao nível de } \\
98,5 \% \text { confiança. }\end{array}$ & $\begin{array}{l}\text { Normalidade não } \\
\text { rejeitada ao nível de } \\
\text { 99,95\% confiança. }\end{array}$ & $\begin{array}{l}\text { Normalidade não } \\
\text { rejeitada ao nível de } \\
98,2 \% \text { confiança. }\end{array}$ \\
\hline
\end{tabular}

Fonte: Dados da pesquisa.

Nota: Testes realizados no software STATA versão 9.1. 


\subsection{Estimação da Variável Dependente - Risco}

O constructo utilizado como inferência a proxy de risco neste trabalho é o índice beta obtido na base de dados do Economática. Utilizou-se o modelo de cálculo do beta do próprio Economática que o faz pelo método da variação do preço de mercado das ações em relação ao índice. Uma alternativa à utilização do beta calculado pelo Economática seria realizar o cálculo manualmente, promovendo a regressão do retorno das ações de cada uma das empresas com o índice de mercado, ano a ano. Todavia seria necessária a realização de pelo menos 223 regressões. Como não foi identificada pelo autor nenhuma restrição ao cálculo proposto pelo Economática, tal ação, além de pouco viável, se mostrou ainda desnecessária.

Segundo Damodaran (2002), a melhor maneira para se obter o beta de uma empresa é utilizando a métrica fundamentalista, sua abordagem em toda sua obra é orientada para o cálculo do valuation. Neste trabalho, cujo propósito e hipótese são o risco percebido pelo mercado financeiro, assume-se essa metodologia de cálculo sem considerá-la uma delimitação da pesquisa.

Utilizou-se no trabalho o beta defasado de três meses da divulgação da DVA, ou seja, o calculado em $1^{\circ}$ de abril do ano seguinte ao da divulgação da DVA, com o objetivo de ter maior assertividade ao fato de os demonstrativos das empresas já terem sido divulgados ao mercado. Para seu cálculo, foi considerado o período de 24 meses e intervalos semanais.

Faz-se importante considerar que, segundo Damodaran (2002, p. 187), existe um trade-off para as escolhas de períodos maiores ou menores para o cálculo do beta. $\mathrm{O}$ primeiro agrega um maior grau de liberdade à regressão aumentando a precisão do resultado, enquanto que o segundo estima as circunstâncias mais recentes que influenciaram o risco de mercado da corporação.

Utilizou-se, para a estimação do beta desta pesquisa, o período de 24 meses, captando da melhor forma os acontecimentos mais recentes que podem influenciar o risco da organização. Com relação ao intervalo da medida adotada, ainda recorrendo a Damodaran (2002, p. 187), tem-se que, em intervalos curtos de retorno da ação, sejam eles diários ou intraday, aumentam o número de observações da regressão e seu grau de liberdade, embora, em contraponto, aumentem o viés da regressão ao que se chama de nontrading.

Entende-se assim que o período de 24 meses com intervalos semanais seja a melhor escolha, dentro do trade-off de precisão do cálculo, efeito nontrading e a sensibilidade da variável aos acontecimentos mais recentes. Cita Damodaran (2002, p. 187) que estes são os parâmetros utilizados pela Bloomberg, enquanto que Value Line e Standard \& Poor's utilizam períodos de cinco anos e intervalos mensais.

\subsection{Variáveis de Controle}

Todas as variáveis de controle utilizadas neste trabalho foram obtidas da base de dados do Economática. Várias são as pesquisas científicas que se propuseram a identificar os fatores determinantes e que influenciam o risco de mercado das empresas.

No Quadro 2, resenha-se o referencial teórico de algumas destas pesquisas, concentrando-se naquelas que se propuseram identificar os efeitos determinantes do risco sistemático do mercado brasileiro. 
Quadro 2- Alguns dos estudos e fatores determinantes encontrados para explicação do risco de mercado das empresas brasileiras

\begin{tabular}{|c|c|c|c|c|c|}
\hline Variável & Forma de Mensuração & $\begin{array}{l}\text { Oda } \text { et al. } \\
\text { (2005) }\end{array}$ & $\begin{array}{l}\text { Antunes e } \\
\text { Guedes } \\
\text { (2006) }\end{array}$ & $\begin{array}{l}\text { Fernandes } \\
(2007)\end{array}$ & $\begin{array}{l}\text { Silva e } \\
\text { Quelhas } \\
\text { (2006) }\end{array}$ \\
\hline ALAF: AlaFin & $\begin{array}{l}\text { (1) NÃO IDENTIFICADA } \\
\text { NA PESQUISA }\end{array}$ & $\begin{array}{l}\text { Significativo / } \\
+\end{array}$ & & & \\
\hline \multirow[t]{2}{*}{$\begin{array}{l}\text { ALAVANCAGEM } \\
\text { FINANCEIRA }\end{array}$} & $\begin{array}{l}\text { (2) EBIT (LUCRO ANTES } \\
\text { DOS JUROS E DO } \\
\text { IMPOSTO DE RENDA) / } \\
\text { DIVIDA LIQUIDA DA } \\
\text { EMPRESA }\end{array}$ & & & $\begin{array}{l}\text { Significativo / } \\
+\end{array}$ & \\
\hline & $\begin{array}{l}\text { (3) COEFICIENTE DA } \\
\text { VARIAÇÃO DOS } \\
\text { VALORES DA } \\
\text { ALAVANCAGEM } \\
\text { FINANCEIRA ÚLTIMOS } \\
5 \text { ANOS } \\
\end{array}$ & & & Significativo / & \\
\hline \multirow{3}{*}{$\begin{array}{l}\text { RENT: } \\
\text { RentAt } \\
\text { RENTABILIDADE }\end{array}$} & $\begin{array}{l}\text { (1) RELAÇÃO DO } \\
\text { LUCRO LIQUIDO SOBRE } \\
\text { PATRIMÔNIO LIQUIDO }\end{array}$ & & & Significativo / & \\
\hline & $\begin{array}{l}\text { (2) COEFICIENTE DA } \\
\text { VARIAÇÃO DOS } \\
\text { VALORES DA } \\
\text { RENTABILIDADE DOS } \\
\text { ÚLTIMOS } 5 \text { ANOS } \\
\end{array}$ & & & Significativo / & \\
\hline & $\begin{array}{l}\text { (3) DESVIO-PADRÃO DO } \\
\text { QUOCIENTE LUCRO } \\
\text { SOBRE PREÇO }\end{array}$ & & & & $\begin{array}{l}\text { Não } \\
\text { Significativo }\end{array}$ \\
\hline \multirow{3}{*}{$\begin{array}{l}\text { ENDV: } \\
\text { Exig / PL } \\
\text { ENDIVIDAMENTO }\end{array}$} & $\begin{array}{l}\text { (1) EXIGIVEL TOTAL / } \\
\text { PL }\end{array}$ & & $\begin{array}{l}\text { Não } \\
\text { Significativo }\end{array}$ & & \\
\hline & $\begin{array}{l}\text { (2) DÍVIDA FINANCEIRA } \\
\text { BRUTA / PL } \\
\end{array}$ & & $\begin{array}{l}\text { Não } \\
\text { Significativo } \\
\end{array}$ & & \\
\hline & $\begin{array}{l}\text { (3) DIVIDA TOTAL } \\
\text { SOBRE ATIVO TOTAL }\end{array}$ & & & & Significativo / \\
\hline $\begin{array}{l}\text { LIQD: } \\
\text { LiqGer }\end{array}$ & $\begin{array}{l}\text { (1) NÃO IDENTIFICADA } \\
\text { NA PESQUISA }\end{array}$ & $\begin{array}{l}\text { Não } \\
\text { Significativo } \\
\end{array}$ & & & \\
\hline \multirow[t]{3}{*}{$\begin{array}{l}\text { LIQUIDEZ } \\
\text { FINANCEIRA }\end{array}$} & $\begin{array}{l}\text { (2) ATIVO CIRCULANTE } \\
\text { SOBRE PASSIVO } \\
\text { CIRCULANTE }\end{array}$ & & & & $\begin{array}{l}\text { Não } \\
\text { Significativo }\end{array}$ \\
\hline & $\begin{array}{l}\text { (3) RELAÇÃO ENTRE O } \\
\text { ATIVO CIRCULANTE E } \\
\text { O PASSIVO } \\
\text { CIRCULANTE }\end{array}$ & & & $\begin{array}{l}\text { Não } \\
\text { Significativo }\end{array}$ & \\
\hline & $\begin{array}{l}\text { (4) COEFICIENTE DA } \\
\text { VARIAÇÃO DOS } \\
\text { VALORES DA LIQUIDEZ } \\
\text { ÚLTIMOS } 5 \text { ANOS }\end{array}$ & & & $\begin{array}{l}\text { Significativo / } \\
+\end{array}$ & \\
\hline \multirow{2}{*}{$\begin{array}{l}\text { DIVY: } \\
\text { Div Yld (fim) } \\
\text { DIVIDENDOS }\end{array}$} & $\begin{array}{l}\text { (1) RELAÇÃO } \\
\text { DIVIDENDO SOBRE } \\
\text { LUCRO }\end{array}$ & & & & Significativo / \\
\hline & $\begin{array}{l}\text { (2) NÃO IDENTIFICADA } \\
\text { NA PESQUISA }\end{array}$ & Significativo / & & & \\
\hline \multirow{2}{*}{$\begin{array}{l}\text { LNAT: } \\
\text { Ativo Tot } \\
\text { TAMANHO }\end{array}$} & $\begin{array}{l}\text { (1) TAMANHO DO } \\
\text { ATIVO }\end{array}$ & $\begin{array}{l}\text { Não } \\
\text { Significativo }\end{array}$ & & & \\
\hline & (2) ATIVO TOTAL & & & $\begin{array}{l}\text { Não } \\
\text { Significativo }\end{array}$ & \\
\hline $\begin{array}{l}\text { Obs.: Aplicado pelo } \\
\text { autor função } \operatorname{LN}(\mathrm{x})\end{array}$ & (3) LOG ATIVO TOTAL & & & $\begin{array}{l}\text { Significativo / } \\
+ \\
\end{array}$ & $\begin{array}{l}\text { Significativo / } \\
+\end{array}$ \\
\hline
\end{tabular}




\begin{tabular}{|c|c|c|c|}
\hline $\begin{array}{l}\text { sobre o valor obtido } \\
\text { do economática. }\end{array}$ & $\begin{array}{l}\text { (4) COEFICIENTE DA } \\
\text { VARIAÇÃO DOS } \\
\text { VALORES DO ATIVO } \\
\text { ÚLTIMOS } 5 \text { ANOS } \\
\end{array}$ & & Significativo / \\
\hline $\begin{array}{l}\text { ESTC: } \\
\text { DivBr/Ativo } \\
\text { ESTRUTURA DE } \\
\text { CAPITAL }\end{array}$ & $\begin{array}{l}\text { (1) MONTANTE DÍVIDAS } \\
\text { / VALOR MERCADO }\end{array}$ & $\begin{array}{l}\text { Significativo / } \\
+\end{array}$ & \\
\hline
\end{tabular}

Legenda: Significância da relação / sinal encontrado entre a relação quando significativo.

Fonte: Oda et al. (2005); Antunes e Guedes (2006); Fernandes (2007); Silva e Quelhas (2006).

\subsection{Modelo Proposto para o Teste da Hipótese}

Como é objetivo desta pesquisa observar a relação entre duas variáveis, risco em relação ao mercado financeiro e planejamento tributário eficiente, propõe-se a equação (5) polinomial a seguir. Antes, faz-se necessário dar a notação adequada às variáveis para melhor compreensão do texto. Define-se RISCO como a variável dependente neste trabalho, que é o constructo de risco de mercado (beta) e que, por sua vez, é a proxy de "risco em relação ao mercado financeiro". E define-se a variável independente como IPTE, que é o constructo aqui proposto para tax avoidance com governança e que, por sua vez, é a proxy de "planejamento tributário eficiente". A estimação dessas variáveis ver-se-á em seguida.

$$
\begin{gathered}
\mathrm{RISCO}_{\mathrm{i}(\mathrm{t}+0.25)}=\alpha_{\mathrm{i}}+\beta_{1} * \mathrm{IPTE}_{\mathrm{it}}+\beta_{2} * \mathrm{ALAF}_{\mathrm{it}}+\beta_{3} * \mathrm{RENT}_{\mathrm{it}}+\beta_{4} * \mathrm{ENDV}_{\mathrm{it}}+ \\
\beta_{5} * \mathrm{LIQD}_{\mathrm{it}}+\beta_{6} * \mathrm{DIVY}_{\mathrm{it}}+\beta_{7} * \mathrm{LNAT}_{\mathrm{it}}+\beta_{8} * \mathrm{ESTC}_{\mathrm{it}}+\zeta_{\mathrm{it}}
\end{gathered}
$$

Onde,

- $\operatorname{RISCO}_{\mathrm{i}(\mathrm{t}+0.25)}$ : Risco de mercado (beta) da empresa i no ano $\mathrm{t}+0.25$, ou seja defasado de 3 meses, sendo auferido em $1^{\circ}$ de abril do ano posterior;

- IPTE $_{\mathrm{it}}$ : Índice de Planejamento tributário eficiente da empresa i no último dia do ano t;

- $\mathrm{ALAF}_{\mathrm{it}}$ : Alavancagem Financeira da empresa i no último dia do ano t;

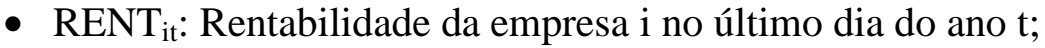

- $\mathrm{ENDV}_{\mathrm{it}}$ : Endividamento da empresa i no último dia do ano t;

- LIQD $D_{i t}$ : Liquidez da empresa i no último dia do ano t;

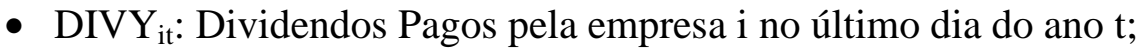

- LNAT $_{\text {it: }}$ Logaritmo do Tamanho da empresa i no último dia do ano t;

- ESTC $_{\text {it }}$ : Estrutura de Capital da empresa i no último dia do ano t;

- $\alpha_{i}$ : Constante de efeito fixo do modelo;

- $\zeta_{\text {it: }}$ : Erro do modelo; e

- $\beta \mathrm{n}$ : Coeficiente de regressão da variável n.

\section{Apresentação e Avaliação dos Resultados}

Concluído o processo de apuração das medidas de risco de mercado e de tax avoidance, cujo objetivo principal foi a determinação das variáveis RISCO e IPTE, além das 
variáveis de controle do modelo, foram realizados os testes de associação entre elas, condição para se rejeitar ou não a hipótese aventada nesta pesquisa.

Na realização dos testes estatísticos, utilizou-se o modelo proposto na equação (8) e o método OLS para a estimação de dados em painel por efeitos fixos, que se mostrou, pelos testes estatísticos realizados, como o melhor estimador frente aos de efeitos aleatórios ou constantes (pooled).

Primeiro, o teste do multiplicador de Lagrange foi realizado para verificar a inexistência de efeitos aleatórios, que é a hipótese nula dessa estatística. $\mathrm{O}$ valor apurado por esse teste foi de 58,28, o qual permitiu, ao nível de significância de $0,01 \%$, rejeitar-se a hipótese nula, evidenciando que os estimadores por efeitos fixos ou aleatórios seriam mais adequados ao modelo, do que os de efeitos constantes (pooled).

Em seguida, realizou-se o teste de Hausman para definir a escolha dentre os estimadores de efeitos fixo e os de efeitos aleatórios. O valor calculado no teste foi de 17,07, o qual permitiu, ao nível de significância de $2,94 \%$, rejeitar a hipótese nula que supõe que as diferenças entre os coeficientes desses dois estimadores não são sistemáticas.

Sendo assim, pelos testes demonstrados, conclui-se que há evidências estatísticas para considerar que a estimação do modelo pelos efeitos fixos apresenta melhores resultados em comparação à estimação por efeitos aleatórios, ou mesmo a estimação pelos efeitos constantes (pooled).

\subsection{Teste de Associação entre Risco de Mercado e Tax Avoidance}

Utilizando-se, pois, o método do OLS, a estimação por efeitos fixos e o software estatístico STATA em sua versão 9.1, os dados obtidos e tratados no trabalho foram lançados ao modelo proposto e os resultados da associação entre as variáveis seguem apresentados na tabela 4 a seguir.

Os resultados evidenciam que o coeficiente IPTE apresenta-se significativo e negativamente relacionado com o RISCO, consistente com as expectativas teóricas levantadas nesta pesquisa. Assim sendo, não há evidências para se rejeitar a hipótese deste trabalho a um nível de confiança de 90\%. Pode-se assim inferir, com base nessa constatação e no desenvolvimento das variáveis, que quanto maior forem as ações de tax avoidance da empresa, substanciadas com a prática de governança corporativa, menor será seu risco de mercado (beta), e, em última instância, quanto maior for o nível de eficiência em planejamento tributário de uma empresa, menor será o seu risco em relação ao mercado financeiro, hipótese do trabalho.

Ainda, observa-se na apresentação dos resultados com base nas evidências estatísticas, que o risco de mercado apresenta-se negativamente relacionado com a liquidez financeira da empresa, ou seja, com sua capacidade de pagamento, e positivamente relacionado com o seu tamanho. Significa dizer que, no Brasil, investir em empresas menos líquidas e maiores é mais arriscado. A relação inversa da liquidez financeira com o risco faz bastante sentido para este autor, a medida que as empresas que demonstram menor capacidade de pagamento de suas obrigações se mostram mais arriscadas que as demais. Essa relação inversa já havia sido identificada antes por Fernandes (2007), embora só percebida tal relação com a variação da variável e não diretamente com ela.

A relação positiva entre risco e tamanho foi identificada por Fernandes (2007) e Silva e Quelhas (2006) em seus respectivos trabalhos. Corrobora este tema o fato de, no período em 
questão, 2005 a 2009, muitas empresas de menor porte terem aberto seu capital, tendo sido percebida boa aceitação de suas ações no mercado brasileiro, enquanto que as grandes, e com características mais globais, enfrentaram uma enorme crise mundial. Mesmo que o Brasil tenha sido um dos países que menos percebeu esta grande crise iniciada em meados de 2008, houve aqui empresas e setores muito afetados, como o siderúrgico, metalúrgico, mineração, papel e celulose, justamente aqueles de capital intensivo, geralmente formados por empresas de grande porte.

Tabela 4 - Resultados obtidos pela aplicação da regressão múltipla à amostra da pesquisa

\begin{tabular}{lrrr}
\hline Variável Independente: RISCO & & & \\
Empresas: 86 & & & \\
Periodo: 2005 à 2009 & Coeficiente (Significância) \\
\hline Variáveis Dependentes & $-5,86 \mathrm{E}-02$ & $(*)$ \\
IPTE & $-5,18 \mathrm{E}-05$ & \\
ALAF & $-6,79 \mathrm{E}-04$ & \\
RENT & $-3,77 \mathrm{E}-05$ & \\
ENDV & $-9,17 \mathrm{E}-02$ & $(*)$ \\
LIQD & $-5,36 \mathrm{E}-03$ & \\
DIVY & $1,81 \mathrm{E}-01$ & $(*)$ \\
LNAT & $-7,92 \mathrm{E}-04$ & \\
ESTC & $-1,91 \mathrm{E}+00$ & \\
cons. & 0,1126 & \\
prob $>$ F & 0,0937 & \\
$r$-sq & 223 & \\
Obs & & & \\
(*) Sig. $10 \% ;(* *)$ Sig. 5\%; (**) Sig. $1 \%$ & & & \\
\hline
\end{tabular}

Fonte: Dados da pesquisa.

Nota 1: Método do OLS e estimador de efeitos fixos para dados em painel.

Nota 2: Testes realizados no software STATA versão 9.1.

\subsection{Análise de Sensibilidade do Modelo à Mensuração do IPTE}

Com o objetivo de avaliarmos a sensibilidade do modelo à mensuração da variável IPTE, propõe-se uma matriz de estimativas de valores ao vetor $\mathrm{FGC}_{\mathrm{m}}$, que se denominou anteriormente de fator de atenuação pela evidenciação de menor nível de governança corporativa. Apresentam-se assim seis propostas de valores e então avalia-se a sensibilidade do modelo aos valores utilizados no cálculo da variável IPTE, em função da atenuação aplicada.

No Quadro 3, seguem os valores propostos, sendo que, na linha $1\left(\mathrm{FGC}_{1}\right)$, têm-se um maior rigor de evidenciação de governança, decrescendo esse rigor até o extremo, linha 6 $\left(\mathrm{FGC}_{6}\right)$, em que a evidenciação de governança é desconsiderada completamente no cálculo da variável.

Quadro 3 - Matriz com propostas diferenciadas de valores ao vetor $\left(\mathrm{FGC}_{\mathrm{m}}\right)$ utilizado no cálculo do IPTE

\begin{tabular}{cccccl}
\hline Sem GC & Nível 1 & Nível 2 & $\begin{array}{l}\text { Novo } \\
\text { Mercado }\end{array}$ & Obs. \\
\hline $\mathbf{C G F}_{1}$ & 0,1 & 0,7 & 0,8 & 1 & $\begin{array}{l}\text { Maior influência da Governança Corporativa à } \\
\text { variável IPTE. }\end{array}$ \\
\hline
\end{tabular}


Planejamento tributário eficiente: uma análise de sua relação com o risco de mercado...

\begin{tabular}{lccccl}
\hline $\mathbf{C G F}_{2}$ & 0,1 & 0,85 & 0,9 & 1 & $\begin{array}{l}\text { Vetor que proporcionou a maior significância } \\
\text { das variáveis. }\end{array}$ \\
$\mathbf{C G F}_{\mathbf{3}}$ & 0,2 & 0,75 & 0,85 & 1 & \\
$\mathbf{C G F}_{\mathbf{4}}$ & 0,3 & 0,8 & 0,9 & 1 & \\
$\mathbf{C G F}_{\mathbf{5}}$ & 0,5 & 0,8 & 0,9 & 1 & \\
$\mathbf{C G F}_{\mathbf{6}}$ & 1 & 1 & 1 & 1 & $\begin{array}{l}\text { Nenhuma influência da Governança Corporativa } \\
\text { à variável IPTE. }\end{array}$ \\
\hline
\end{tabular}

Fonte: Dados da pesquisa.

Assim, têm-se os resultados desta análise de sensibilidade na Tabela 5 a seguir:

Tabela 5 - Análise de sensibilidade do modelo à mensuração do IPTE pelas alterações do $\left(\right.$ FGC $\left._{\mathrm{m}}\right)$

\begin{tabular}{|c|c|c|c|c|c|c|c|c|c|c|c|c|}
\hline \multicolumn{13}{|c|}{$\begin{array}{l}\text { Dados em painel } \\
\text { Variável Independente: RISCO } \\
\text { Empresas: } 86 \\
\text { Período: } 2005 \text { à } 2009\end{array}$} \\
\hline \multirow[b]{2}{*}{ IPTE } & \multicolumn{2}{|c|}{$\begin{array}{c}\text { (coluna 1) } \\
F G C_{I}\end{array}$} & \multicolumn{2}{|c|}{$\begin{array}{c}\text { (coluna 2) } \\
F_{G C_{2}}\end{array}$} & \multicolumn{2}{|c|}{$\begin{array}{c}\text { (coluna } 3) \\
F_{G C} C_{3}\end{array}$} & \multicolumn{2}{|c|}{$\begin{array}{c}\text { (coluna } 4) \\
F_{G C}\end{array}$} & \multicolumn{2}{|c|}{$\begin{array}{c}\text { (coluna 5) } \\
F_{G C}\end{array}$} & \multicolumn{2}{|c|}{$\begin{array}{c}\text { (coluna } 6) \\
F G C_{6}\end{array}$} \\
\hline & $-6,1 \mathrm{E}-02$ & $*(\mathbf{0}, 080)$ & $-5,9 \mathrm{E}-02$ & $*(\mathbf{0 , 0 7 3 )}$ & $-5,8 \mathrm{E}-02$ & ${ }^{*}(\mathbf{0}, \mathbf{0 8 6})$ & $-5,6 \mathrm{E}-02$ & $*(0,092)$ & $-5,2 \mathrm{E}-02$ & $(0,116)$ & $-3,9 \mathrm{E}-02$ & $(0,177)$ \\
\hline ALAF & $-5,1 \mathrm{E}-05$ & & $-5,2 \mathrm{E}-05$ & & $-5,1 \mathrm{E}-05$ & & $-5,2 \mathrm{E}-05$ & & $-5,2 \mathrm{E}-05$ & & $-5,5 \mathrm{E}-05$ & \\
\hline RENT & $-6,4 \mathrm{E}-04$ & & $-6,8 \mathrm{E}-04$ & & $-6,3 \mathrm{E}-04$ & & $-6,2 \mathrm{E}-04$ & & $-6,0 \mathrm{E}-04$ & & $-6,4 \mathrm{E}-04$ & \\
\hline ENDV & $-3,7 \mathrm{E}-05$ & & $-3,8 \mathrm{E}-05$ & & $-3,7 \mathrm{E}-05$ & & $-3,8 \mathrm{E}-05$ & & $-3,9 \mathrm{E}-05$ & & $-4,0 \mathrm{E}-05$ & \\
\hline LIQD & $-9,2 \mathrm{E}-02$ & $*(\mathbf{0 , 0 5 7 )}$ & $-9,2 \mathrm{E}-02$ & $*(\mathbf{0 , 0 5 6})$ & $-9,2 \mathrm{E}-02$ & $*(\mathbf{0 , 0 5 7})$ & $-9,2 \mathrm{E}-02$ & $*(\mathbf{0}, 057)$ & $-9,2 \mathrm{E}-02$ & $*(\mathbf{0}, 057)$ & $-9,3 \mathrm{E}-02$ & $*(\mathbf{0}, 055)$ \\
\hline DIVY & $-5,4 \mathrm{E}-03$ & & $-5,4 \mathrm{E}-03$ & & $-5,4 \mathrm{E}-03$ & & $-5,4 \mathrm{E}-03$ & & $-5,4 \mathrm{E}-03$ & & $-5,5 \mathrm{E}-03$ & \\
\hline LNAT & $1,8 \mathrm{E}-01$ & $*(\mathbf{0 , 0 5 2})$ & $1,8 \mathrm{E}-01$ & $*(\mathbf{0 , 0 5 1})$ & $1,8 \mathrm{E}-01$ & $*(0,056)$ & 1,8E-01 & $*(0,059)$ & $1,7 \mathrm{E}-01$ & $*(0,067)$ & $1,7 \mathrm{E}-01$ & $*(\mathbf{0 , 0 7 8 )}$ \\
\hline ESTC & $-7,8 \mathrm{E}-04$ & & $-7,9 \mathrm{E}-04$ & & $-7,1 \mathrm{E}-04$ & & $-6,5 \mathrm{E}-04$ & & $-5,3 \mathrm{E}-04$ & & $-3,5 \mathrm{E}-04$ & \\
\hline cons. & $-1,9 \mathrm{E}+00$ & & $-1,9 \mathrm{E}+00$ & & $-1,9 \mathrm{E}+00$ & & $-1,8 \mathrm{E}+00$ & & $-1,8 \mathrm{E}+00$ & & $-1,7 \mathrm{E}+00$ & \\
\hline$p r o b>F$ & 0,1184 & & 0,1126 & & 0,1222 & & 0,1264 & & 0,1417 & & 0,1724 & \\
\hline$r-s q$ & 0,0926 & & 0,0937 & & 0,0918 & & 0,0911 & & 0,0884 & & 0,0838 & \\
\hline Obs & 223 & & 223 & & 223 & & 223 & & 223 & & 223 & \\
\hline
\end{tabular}

Fonte: Dados da pesquisa.

Nota: Testes realizados no software STATA versão 9.1.

Observou-se com base nos resultados encontrados que, à medida que a variável IPTE despreza a influência da governança corporativa da empresa na composição da variável de planejamento tributário eficiente, perde-se significância dela com o risco. Isso ocorre da coluna 2 em diante.

No extremo em que não se tem no modelo qualquer influência de governança ao planejamento tributário, coluna 6 , ou quando quase não se tem, coluna 5, essa correlação deixa de ser significativa. Todavia, observa-se ainda que a melhor significância entre as variáveis não ocorre na menor atenuação proposta, coluna 1, identificando-se assim um ponto de inferência da relação.

Uma explicação ao surgimento desse ponto pode ser dada pela saturação provocada à variável, à medida que prevalece nela os efeitos de governança, anulando-se os demais efeitos igualmente importantes à medida do constructo de planejamento tributário eficiente, acima discutidos. Essa constatação corrobora a presente pesquisa, demostrando que a significância da relação existente entre as variáveis é reduzida, à medida que se sobrepõem os efeitos de 
governança aos demais atributos necessários ao planejamento tributário eficiente. Talvez essa constatação possa ser mais bem explorada em outros estudos sobre a matéria.

Essa sensibilidade do modelo à prática de governança mostra-se completamente condizente com o referencial teórico abordado nesta pesquisa, tornando-se esta mais uma pesquisa a corroborar o assunto, que é ainda recente, embora comece a ser ampliada sua discussão acadêmica.

\section{Conclusão}

No contexto atual, em que a carga tributária é um fator relevante para a composição de custos das empresas, o planejamento tributário se apresenta como uma ferramenta importante para a construção de uma organização eficaz, embora pouco ainda se saiba sobre as consequências que essa prática acarreta. Neste trabalho, o autor se propôs a pesquisar se o planejamento tributário eficiente reduz o risco de mercado das empresas.

Concluiu-se que a eficiência tributária de uma organização, alcançada pelo exercício bem sucedido em atividades de planejamento tributário, promove uma redução do seu risco em relação ao mercado de capitais.

Evidenciou-se também que, para o alcance da eficiência em planejamento tributário, faz-se essencial que as empresas sejam transparentes em suas ações e haja um perfeito alinhamento dos seus interesses aos dos agentes, situação esta encontrada nas empresas que praticam a governança corporativa em sua gestão.

Ressalta-se, assim, que não é qualquer tipo de planejamento tributário que leva à redução de risco das empresas. Aqueles feitos de forma inócua, obscura, oculta, visando ao interesse dos próprios administradores, que consideram pura e simplesmente o seu bônus de curto prazo, dissonantes dos interesses da organização, parecem ser percebidos pelo mercado financeiro, e não são a eles oferecidos o mesmo benefício do que os realizados dentro de uma ambiência de clareza e governança.

Esta pesquisa veio, assim, a corroborar com a moderna teoria de corporate tax avoidance e os recentes trabalhos desenvolvidos por Wilson (2009) e Desai e Dharmapala (2009), encontrando também aqui evidências de que o tax avoidance, quando exercido, concomitantemente, com as práticas de governança corporativa, e apenas dessa forma, levam à melhoria do desempenho das organizações. De outro lado, quando exercido sem as práticas de governança, não são encontradas as melhorias esperadas.

Ademais, foi proposto no trabalho um constructo novo para a variável Planejamento Tributário Eficiente, o IPTE, tendo sido definido no estudo alguns alicerces que fundamentam a sua forma de estimação. São eles: all parts, all costs, all taxes, conforming avoidance, implicit taxes, taxes clienteles e carga tributária oculta.

Para a construção teórica desta pesquisa buscou-se um arcabouço interdisciplinar, envolvendo a matéria de planejamento tributário e a teoria de tax avoidance, além de estudos na área de finanças e risco. Todos eles abordados em conjunto com o framework de governança corporativa e a teoria dos agentes.

Algumas limitações deste trabalho foram identificadas, e outras delimitações foram impostas à pesquisa pelo autor e serão aqui apresentadas, até para que sirvam como ponto de partida para novos trabalhos relacionados ao tema. 
A primeira delas refere-se à amostra obtida, que representa parte do universo das empresas que, voluntariamente, responderam à pesquisa Melhores \& Maiores e divulgaram seu DVA. No momento em que se torna obrigatória a apresentação desse demonstrativo, dados sem essa discricionariedade, e em maior quantidade, podem ser alcançados, possibilitando repetir-se a presente pesquisa com uma amostra mais representativa e com séries temporais mais longas, o que permitiria, inclusive, acrescer ao constructo proposto a medida de long run comentada.

Além disso, utilizou-se como constructo de risco percebido pelo mercado o beta, proveniente da teoria do CAPM. Futuras pesquisas poderão explorar a relação entre o planejamento tributário eficiente e o risco idiossincrático. Pode-se abordar também o tema pela teoria do retorno anormal do preço do ativo, a exemplo de Wilson (2009).

Não obstante, pesquisas que venham a oferecer propostas de estimação dos tributos ocultos das empresas também seriam muito bem-vindas. Os trabalhos realizados, como este, assumem premissas sobre o tema, restringindo a análise da matéria com maior acurácia. Ainda que se reconheça que se trate de dados confidenciais e de difícil obtenção da organização, mensurá-los com precisão seria de grande valia para o aprofundamento da matéria.

Outra limitação identificada pelo autor refere-se à estimação do IPTE, que condensou na variável o indicador de governança, em vez de tê-la no modelo em uma variável independente. Isso porque a medida de governança utilizada no trabalho, a classificação dada pela CVM, possui pouca sensibilidade da variação no tempo e assim seus efeitos seriam perdidos no método de estimação de dados em painel por efeitos fixos utilizados nesta pesquisa.

Sugere-se então a possibilidade de realização de pesquisas que venham a trabalhar com outro constructo para a variável de governança. Um que seja mais sensível à percepção de sua variação no tempo, e assim seja possível trabalhar com variáveis distintas, sendo uma para o planejamento tributário, e outra para a governança, podendo ser avaliada, inclusive, a robustez do modelo.

Também, à medida que se torna possível a utilização de dados com maior quantidade de registros no ano, haja vista a recente obrigatoriedade da divulgação do DVA pelas empresas, pode-se trabalhar regressões apenas com dados em cross-section, e também, nesse caso, é possível utilizar variáveis distintas.

Por fim, faz-se importante mencionar o possível impacto dos resultados aqui encontrados, que diz respeito ao aumento marginal do valor de mercado das empresas que praticam o planejamento tributário eficiente, adicionada ao ganho produzido pelo reflexo direto dessa prática ao fluxo de caixa da organização. Isso porque, quando o risco de mercado das empresas é reduzido, se conclui, com base no CAPM, que se reduz também o custo de capital das empresas, e, por consequência, há um aumento marginal do seu valor.

Assim, com base nos resultados aqui obtidos, pressupõe-se que o planejamento tributário eficiente aumente o valor e o retorno anormal das empresas brasileiras, a exemplo do que concluiu os estudos de Wilson (2009) e Desai e Dharmapala (2009), realizados em outros mercados. 


\section{Referências}

AMARAL, G. L.; OLENIKE, J. E.; AMARAL, L. M. F.; STEINBRUCH, F. Carga tributária brasileira de $2010 \quad$ - Prévia, 2011. Disponível em <http://www.ibpt.com.br/home/publicacao.view.php?publicacao_id=13913>. Acesso em: abril/2012.

ANTUNES, G. A.; GUEDES, G. R. Risco de insolvência e risco sistemático: relação teórica não verificada na BOVESPA. RAE - EDIÇÃO ESPECIAL MINAS GERAIS, v. 46, p. 58-71, 2006.

AYERS, B.; LAPLANTE, S.; MCGUIRE, S. Credit rankings and taxes: the effect of book-tax differences on ratings changes. Contemporary Accounting Research, v. 27, n. 2, p. 359$402,2010$.

CHEN, K. P.; CHU, C. Internal control vs. external manipulation: a model of corporate income tax evasion. RAND Journal of Economics, v. 36, Issue. 4, p. 151-164, 2005.

COSER, M. B.; ARAÚJO, L. F. O.; LOUZADA, L. C. A relação entre indicador financeiro e o risco de mercado: um teste empírico no mercado brasileiro. Anais... Encontro da ANPAD ENANPAD, 2005.

CROCKER, K.; SLEMROD, J. Corporate tax evasion with agency costs. Journal of Public Economics, v. 89, n. 9, p. 1593-1610, 2005.

DAMODARAN, A. Investment valuation: tools and techniques for determining the value of any asset. 2. ed. Willey Finance, 2002.

DANTAS, J. A.; LUSTOSA, P. R. B.; DE MEDEIROS, O. R. Reação do mercado à alavancagem operacional: um estudo empírico no Brasil. Anais... Encontro da ANPAD ENANPAD, 2005.

DESAI, M.; DHARMAPALA, D. Corporate tax avoidance and firm value. Review of Economics and Statistics, v. 91, n.3, p. 537-546, 2009.

DYRENG, S.; HANLON, M.; MAYDEW, E. Long-run corporate tax avoidance. The Accounting Review, v. 83, n.1, p. 61-82, 2008.

FAMA, E. F.; FRENCH, K. R. The cross-section of expected stock returns. The Journal of Finance, v. 47, n.2, p. 427-465, 1992.

FERNANDES, Â. S. Análise empírica de fatores determinantes do risco sistemático das empresas brasileiras. Dissertação de mestrado apresentada ao Programa de Pós-Graduação em Administração da Universidade de Brasília, 2007. 
GALLO, M. F. A relevância da abordagem contábil na mensuração da carga tributária das empresas. Tese de Doutorado em Ciências Contábeis, FIPECAFI/USP, 2007.

GRUCA, T. S.; REGO, L. L. Customer satisfaction, cash flow, and shareholder value. Journal of Marketing, v. 69, n.3 p. 115-130, 2005.

HANLON, M.; HEITZMAN, S., A review of tax research. Journal of Accounting and Economics, v. 50, Issue 2-3, p. 127-178, 2010.

HAFKENSCHEID, R. What effective tax rate lacks as a performance indicator. International Tax Review, v. 21, n. 1 p. 14-17, 2010.

HOU, K.; ROBINSON D. T. Industry concentration and average stock returns. The Journal of Finance, v. 61, Issue: 4, p. 1927-1956, 2006.

JENSEN, M.; MECKLING, W. Theory of the firm: managerial behavior, agency costs and ownership structure. Journal of Financial Economics, v. 3, n. 3 p. 305-360, 1976.

JORION, P. Value at risk: the new benchmark for management financial risk. 2. ed. The McGraw-Hill Companies, Inc., 2001.

MARKOWITZ, H. Portfolio selection. The Journal of Finance, v. 7, p. 77-91, 1952.

ODA, A. L.; YOSHINAGA, C. E.; OKIMURA R. T.; SECURATO J. R. Análise da relação entre indicadores contábeis e betas de mercado das empresas brasileiras negociadas na bolsa de valores de São Paulo no período 1995 - 2003. Anais... Encontro da ANPAD - ENANPAD, 2005.

RECEITA FEDERAL DO BRASIL. Relatório da carga tributária no Brasil - 2009: análise por tributos e bases de incidência, 2010. Disponível em <http://www.receita.fazenda.gov.br/historico/esttributarios/estatisticas/cargatributariabr2009. htm>. Acesso em: março/2012.

RICHARDSON, G. Determinants of tax evasion: a cross-country investigation. Journal of International Accounting Audition and Taxation, v. 15, n. 2, p. 150-169, 2006.

RICHARDSON G. The relationship between culture and tax evasion across countries: additional evidence and extensions. Journal of International Accounting Audition and Taxation, v. 17, n. 1, p. 67-78, 2008.

SCHOLES, M.; WOLFSON, M. Taxes and business strategy: a planning approach. Englewood Cliffs, NJ: Prentice Hall, 1992.

SCHOLES, M.; WOLFSON, M.; HALON, M.; ERICKSON, M.; MAYDEW, E.; SHEVLIN, T. Taxes and business strategy: a planning approach. 5. ed. Prentice Hall, 2014. 
SHARP, W. F. Capital asset prices: a theory of market equilibrium under conditions of risk. The Journal of Finance, v. 19, n. 3, p. 425-442, 1964.

SILVA, L. S. A.; QUELHAS, O. L. G. Sustentabilidade empresarial e o impacto no custo de capital próprio das empresas de capital aberto brasil. Gestão \& Produção, v. 13, p. 385-395, 2006.

SLEMROD, J. The economics of corporate tax selfishness. National Tax Journal, v. 57, n. 6 p. 877-899, 2004.

TSAKUMIS, G. T.; CURATOLA, A. P.; PORCANO, T. M. The relation between national cultural dimensions and tax evasion. Journal of International Accounting Audition and Taxation, v. 16, n. 2, p.131-147, 2007.

TULI, K. R.; BHARADWAJ, S. G. Customer satisfaction and stock returns risk. Journal of Marketing, v. 73, n. 6, p. 184-197, 2009.

WILSON, R. An examination of corporate tax shelter participants. The Accounting Review, v. 84, n. 3, p. 969-999, 2009. 